\title{
Double-diffusive mixed convection flow towards a convectively heated stretching sheet with non- linear thermal radiation
}

\author{
Mrutyunjay Das ${ }^{1}$, Bhupesh K. Mahatha ${ }^{2}$, Raj Nandkeolyar ${ }^{3}$, Subharthi Sarkar ${ }^{*}$ \\ ${ }^{1}$ Department of Mathematics, School of Applied Sciences, Kalinga Institute of Industrial Technology, Bhubaneswar 751024, \\ India \\ ${ }^{2}$ Department of Applied Science, Jharkhand Rai University, Ranchi 835222, India \\ ${ }^{3}$ Department of Mathematics, National Institute of Technology Jamshedpur, Jamshedpur 831014, India
}

Corresponding Author Email: sarkar.ism@gmail.com

https://doi.org/10.18280/ijht.360331

Received: 13 May 2017

Accepted: 2 May 2018

\section{Keywords:}

mixed convection, nanofluid flow, nonlinear thermal radiation, convective heat transfer partial slip, Brownian motion, thermophoresis

\begin{abstract}
An investigation of two dimensional double-diffusive mixed convective flow of a viscous, incompressible, electrically conducting and optically thick nanofluid over a convectively heated stretching sheet is carried out taking into account the effects of non-linear thermal radiation and partial hydrodynamic slip. A similarity solution to the governing non-linear partial differential equations subject to the boundary conditions is obtained using the efficient Spectral Local Linearization Method (SLLM). In order to study the behavioral changes in flow profiles by various non-dimensional flow parameters, the numerical solution for fluid velocity, fluid temperature, and species concentration are illustrated through figures, and the numerical values of skin friction, Nusselt number and Sherwood number are presented in tables. Nanofluid models of this kind are useful in several engineering processes requiring efficient heat and mass exchange mechanisms like catalytic and nuclear reactors, metal extraction, cooling systems and many more.
\end{abstract}

\section{INTRODUCTION}

Theoretical/experimental investigation of double-diffusive mixed convective flow past solid bodies of various shapes have received overwhelming attention during the past decades due to its diverse applications in engineering and technology such as geothermal reservoirs, thermal insulators, chemical catalytic reactors, grain storage, food processing, heat exchanger devices, nuclear waste repositories, chemical catalytic reactors and processes, enhanced recovery of petroleum products (SADG, CBM etc.), underground energy transport etc. Investigation of two-dimensional boundary layer flow past a stretching sheet was initiated by Crane [1], and it is considered as one of the breakthrough investigations of the modern world owing to its remarkable uses in wide-ranging industrial practices. After that, several researchers have embarked in-depth research on the various aspects of viscous incompressible flow past a stretching sheet. Moreover, the study of heat and mass transfer boundary layer flow over a stretching surface is highly significant from the practical point of view because it finds applications in a cooling bath for condensation of hot metallic plates, plastic sheet extrusion using aerodynamic processes, extrusion of a polymer sheet from a dye and many more. Several researchers [2-7] have made significant contributions in analyzing the different features of the flow past a stretching sheet.

Nanofluid describes a liquid suspension containing ultrafine particles Das [8]. These ultrafine particles called nanoparticles are made from various conductive materials such as metals ( $\mathrm{Al}, \mathrm{Cu}, \mathrm{Au}, \mathrm{Ag})$, their metallic oxides $\left(\mathrm{Al}_{2} \mathrm{O}_{3}\right.$, $\mathrm{CuO})$ or nitride ceramics ( $\mathrm{AlN}, \mathrm{SiN})$ and semiconductors $(\mathrm{SiC}$, $\mathrm{TiO}_{2}$ ). The base fluids used are typically $\mathrm{H}_{2} \mathrm{O}, \mathrm{C}_{2} \mathrm{H}_{6} \mathrm{O}_{2}$ (ethylene glycol), $\mathrm{C}_{7} \mathrm{H}_{8}$ (toluene) and oil. Choosing an effective base fluid-particle amalgamation depends on where the nanofluid is going to be applied. Experimental studies [911] show that even with the addition of minute volumetric fraction of nanoparticles, the thermal conductivity of the base liquid can be considerably improved. The energy transport in a nanofluid is supported by the random motion of suspended nanoparticles which is known as the Brownian motion. The enhanced thermal conductivity of a nanofluid combined with the thermal dispersion of particles contribute to an amazing enhancement in the convective heat transfer coefficient which in fact makes the nanofluid a superior heat transfer medium for cooling applications such as electronics cooling, vehicle cooling, cooling of nuclear rods and cylindrical heat pipes. A comprehensive study of thermal conductivity of nanofluids can be found in Boungiorno et al. [12]. Thereafter, several researchers [13-19] have studied nanofluid flow past a stretching surface considering the effects of various physical agents on the boundary layer flow.

In case of fluid flows in microfluidic and nanofluidic mechanical systems, the no slip condition at the solid-fluid interface becomes invalid and must be replaced by slip condition. Keeping in view the importance of such study, Aziz [22] investigated boundary layer flow over a flat plat with slip flow and constant heat flux. Noghrehabadi et al. [21-22] investigated nanofluid flow over stretching sheet taking into account partial slip under different thermal buondary conditions. Turkyilmazoglu [23] considered magnetic field and slip effects on the flow and heat transfer of stagnation point Jeffrey fluid over deformable surfaces. In order to decipher the effect of both natural and forced convection (or mixed convection) on nanofluid flow, recently, 
Turkyilmazoglu [24] and Ramzan et al. [25-26] have investigated mixed convective nanofluid flow considering various aspects of the problem.

One must note that, isothermal or isoflux thermal boundary conditions may not replicate most physical phenomena as in conjugate heat transfer problems when there is an interaction between the convective fluid and conduction through the bounding surface. It may be noted that conjugate/convective thermal boundary conditions are known to appear in numerous instances of the problems in science and engineering viz. optimization of turbine blade cooling systems, design of efficient heat exchangers, combustion in gas turbines, etc. Some of the contributions in nanofluid flow with convective heat transfer are due to Makinde and Aziz [27], Makinde et al. [28], Bhasker Reddy et al. [23], Uddin et al. [30], Mahatha et al. [31] and, most recently, by Ramzan et al. [25-26] and Uddin and Hoque [34].

Recently, there has been a keen interest in studying the effects of non-linear thermal radiation on nanofluid flow under different physical environments. Ramzan et al. [32] have presented a comprehensive study of the effects of non-linear thermal radiation while studying heat and mass transfer nanofluid flow with motile gyrotactic microorganisms. Subsequently, Ramzan et al. [33] have also investigated boundary layer flow of Eyring Powell nanofluid past a constantly moving surface under the influence of nonlinear thermal radiation. Comparison of the heat transfer efficiency of nanofluids is presented by Bubbico et al. [35].

However, as per the best of our knowledge there is no study in literature to address two dimensional double-diffusive mixed convective flow of a viscous, incompressible and optically thick nanofluid fluid over a convectively heated stretching sheet taking into account all the combined effects of non-linear thermal radiation and hydrodynamic partial slip, Brownian motion and thermophoresis. Therefore, in a quest to gain further knowledge on this topic, we have formulated the problem and used highly effective spectral local linearization method to solve the nonlinear system of equations. The results obtained are analyzed through figures and tables.

\section{FORMULATION OF THE PROBLEM}

We consider the two dimensional steady viscous flow of an electrically conducting incompressible nanofluid in the region $y>0$ impelled by a stretching/shrinking permeable surface at $y=0$. In order to stretch the sheet along its length, two equal but opposite forces are delivered on the sheet with a velocity $U_{w}$ $(x)$ in such a way that the position of the origin $\mathrm{O}$ remains fixed (see Fig. 1). A convective heating is applied to the sheet using a hot fluid having temperature $T_{f}$ and heat transfer coefficient $h_{f}$. The effect of non-linear thermal radiation is also taken into account. The symbol $C_{w}$ denotes the solutal concentration near the sheet and $C_{\infty}$ is the ambient solutal concentration. Further, it is considered that there is a partial velocity slip taking place at the fluid solid interface. Taking in consideration of the above assumptions, the equations governing the fluid flow are given below [27-28, 31]:

$$
\frac{\partial u}{\partial x}+\frac{\partial v}{\partial y}=0
$$

$$
\begin{aligned}
& u \frac{\partial u}{\partial x}+v \frac{\partial u}{\partial y}=v \frac{\partial^{2} u}{\partial y^{2}}+\frac{\left(1-C_{\infty}\right) \rho_{f \infty} \beta g\left(T-T_{\infty}\right)}{\rho_{f}} \\
& -\frac{\left(\rho_{p}-\rho_{f \infty}\right) g\left(C-C_{\infty}\right)}{\rho_{f}}, \\
& u \frac{\partial T}{\partial x}+v \frac{\partial T}{\partial y}=\alpha \frac{\partial^{2} T}{\partial y^{2}}-\frac{1}{(\rho c)_{f}} \frac{\partial q_{r}}{\partial y} \\
& +\tau\left[D_{B} \frac{\partial C}{\partial y} \frac{\partial T}{\partial y}+\frac{D_{T}}{T_{\infty}}\left(\frac{\partial T}{\partial y}\right)^{2}\right], \\
& u \frac{\partial C}{\partial x}+v \frac{\partial C}{\partial y}=D_{B} \frac{\partial^{2} C}{\partial y^{2}}+\frac{D_{T}}{T_{\infty}} \frac{\partial^{2} T}{\partial y^{2}},
\end{aligned}
$$

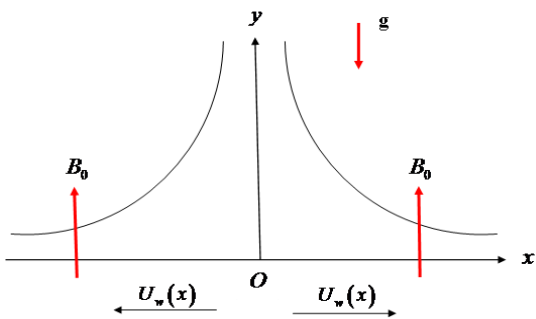

Figure 1. Geometry of the problem

where $u$ and $v$ are velocity components along the $x$ and $y$ axes, respectively, $\alpha$ is thermal diffusivity of the fluid, $v$ is kinematic viscosity, $D_{B}$ is Brownian diffusion coefficient, $D_{T}$ is the thermophoretic diffusion coefficient and $\tau=\frac{(\rho c)_{p}}{(\rho c)_{f}}$ is ratio between the effective heat capacity of the nanoparticle material and heat capacity of the fluid, $\rho$ is fluid density, $c$ is the specific heat at constant pressure and $\rho_{p}$ is the density of the particles

The boundary conditions for the problem are

$$
\begin{aligned}
& u=U_{W}+N_{1} v \frac{a u}{a y}=N_{1} v \frac{a u}{a y}, v=0,-k \frac{a T}{a y}=h_{f}\left(T_{f}-\right. \\
& T), C=C_{w} \text {, at } y=0, u \rightarrow 0, T \rightarrow T_{\infty}, C \rightarrow C_{\infty}, \text { as } y \rightarrow \infty
\end{aligned}
$$

where $N_{1}$ is the velocity slip factor with dimension $(\text { velocity })^{-1}$. We introduce the following dimensionless quantities

$\psi(x, y)=\alpha R a_{x}^{1 / 4} f(\eta), \theta=\frac{\left(T-T_{\infty}\right)}{\left(T_{f}-T_{\infty}\right)}, \theta_{r}=\frac{T_{f}}{T_{\infty}}, \emptyset=\frac{\left(C-C_{\infty}\right)}{\left(C_{w}-C_{\infty}\right)}$

where $\eta=\frac{y}{x} R a_{x}^{1 / 4} \theta_{r}$ is temperature ratio parameter, $\eta$ is the dimensionless stream function, $R a_{x}$ is the local Rayleigh number defined as

$R a_{x}=\frac{\left(1-C_{\infty}\right) g \beta\left(T_{f}-T_{\infty}\right) x^{3}}{v \alpha}$.

The stream function $\psi(x, y)$ is defined as

$u=\frac{a \psi}{a y}, v=-\frac{a \psi}{a x}$ 
This transformation automatically safies the continuity equation (1).

Roseland diffusion approximation [34] has been used to simplify the term due to radiative heat flux

$q_{r}=-\frac{16 \sigma^{*} T^{3}}{3 \alpha^{*}} \frac{\partial T}{\partial y}$

where $\sigma^{*}$ is the Stefan-Boltzmann constant, $\alpha^{*}$ is the Rosseland mean absorption coefficient.

The radiation term $q_{r}$ is simplified in the following way using equation (6), we may write

$T=T_{\infty}\left\{1+\left(\theta_{r}-1\right) \theta\right\}$.

Now, since $\frac{d \theta}{d y}=\frac{R a_{x}^{1 / 4}}{x}$, we have from (10)

$\frac{\partial T}{\partial y}=\left(T_{f}-T_{\infty}\right) \frac{R a_{x}^{1 / 4}}{x} \theta^{\prime}$,

Therefore, eqn. (9), using (10) and (11) become

$q_{r}=\frac{-16 \sigma^{*}}{3 \alpha^{*}} T_{\infty}^{3}\left\{1+\left(\theta_{r}-1\right) \theta\right\}^{3}\left(T_{f}-T_{\infty}\right) \frac{R a_{x}^{1 / 4}}{x} \theta^{\prime}$

Using the aforementioned transformation (8) and the Eqs. (6), (7), (10) and (12), the Eqs. (2), (3) and (4) become

$f^{\prime \prime \prime}+\frac{1}{4 P r}\left(3 f f^{\prime \prime}-2 f^{\prime 2}\right)+\theta-N r \phi=0$,

$\left[1+\frac{4}{3 N_{R}}\left\{1+\left(\theta_{r}-1\right) \theta\right\}^{3}\right] \theta^{\prime \prime}+\frac{3}{4} f \theta^{\prime}+N b \theta^{\prime} \emptyset^{\prime}$

$+\left[N t+\frac{4}{N_{R}}\left(\theta_{r}-1\right)\left\{1+\left(\theta_{r}-1\right) \theta\right\}^{2}\right] \theta^{\prime 2}=0$,

$\phi^{\prime \prime}+\frac{3}{4} \operatorname{Lef} \phi^{\prime}+\frac{N t}{N b} \theta^{\prime \prime}=0$,

subject to the following boundary conditions:

$f(\eta)=0, f^{\prime}(\eta)=\lambda+A f^{\prime \prime}(\eta)$

$\theta^{\prime}(\eta)=-N c[1-\theta(\eta)], \emptyset(\eta)=1$ at $\eta=0$

$f^{\prime}(\eta) \rightarrow 0, \theta(\eta) \rightarrow 0, \emptyset(\eta) \rightarrow 0$ as $\eta \rightarrow \infty$.

The primes in the above equations denote differentiation with respect to $\eta$. The nine parameters are defined by

$\operatorname{Pr}=\frac{v}{\alpha}, N r=\frac{\left(\rho_{p}-\rho_{f}\right)\left(C_{w}-C_{\infty}\right)}{\rho_{f} \beta\left(1-C_{\infty}\right)\left(T_{f}-T_{\infty}\right)}, N b=\frac{\tau D_{B}\left(C_{w}-C_{\infty}\right)}{\alpha}$,

$N t=\frac{\tau D_{T}\left(T_{f}-T_{\infty}\right)}{\alpha T_{\infty}}, \lambda=\frac{a x^{2}}{\alpha \sqrt{R a_{x}}}, L e=\frac{\alpha}{D_{B}}$,

$N c=\frac{h_{f} x^{1 / 4}}{k}\left[\frac{v \alpha}{\left(1-C_{\infty}\right) g \beta\left(T_{f}-T_{\infty}\right)}\right]^{1 / 4}, N_{R}=\frac{K \alpha^{*}}{4 \sigma_{*} T_{\infty}^{3}}, A=\frac{N_{1} v R a_{x}^{1 / 4}}{x}$

where $\operatorname{Pr}$ is the Prandtl number, $N r$ is the buoyancy-ratio parameter, $\mathrm{Nb}$ is the Brownian motion parameter, $N t$ is the thermophoresis number, $\lambda$ is the stretching/shrinking parameter, $L e$ is the Lewis number, $N c$ is the convective parameter, $N_{R}$ is the thermal radiation parameter and $A$ is the momentum slip parameter. As per the formulation, the parameter $N c$ depends on $x$, and therefore, a true similarity could not be achieved. However, this problem could be tactfully solved by choosing the convection heat transfer coefficient $h_{f}$ to be proportional to $x^{-1 / 4}$ so that $N c$ becomes independent of $x$ and a true similarity is achieved. For $N c \rightarrow \infty$ , the convective boundary condition gets reduced to a uniform surface temperature boundary condition used by Kuznetsov and Nield [35]. The convective parameter is related to the traditional Biot number and the Rayleigh number i.e. $N c=$ $\frac{B i_{x}}{R a_{x}^{1 / 4}}$ where $B i_{x}=\frac{h_{f} x}{k}$

Skin friction coefficient $\mathrm{C}_{f}$, the local Nusselt number $N u_{x}$ and the local Sherwood number $S h_{x}$ are very significant physical entities in fluid flow and they are defined as

$C_{f x}=\frac{\tau_{w} x^{2}}{\mu \alpha R a_{x}^{3 / 4}}, N u_{x}=\frac{x q_{w}}{k\left(T_{f}-T_{\infty}\right)}, S h_{x}=\frac{x q_{m}}{D_{B}\left(C_{w}-C_{\infty}\right)}$

where $\tau_{w}, q_{w}$ and $q_{m}$ are the wall shear stress, heat and mass fluxes, respectively, which are given by

$$
\begin{aligned}
\tau_{w} & =\mu\left(\frac{a u}{a y}\right)_{y=0}, q_{w}=-k\left(\frac{a T}{a y}\right)_{y=0}+\left(q_{r}\right)_{y=0} \\
q_{m} & =-D_{B}\left(\frac{\partial C}{\partial y}\right)_{y=0},
\end{aligned}
$$

with $\mu$ and $k$ being the dynamic viscosity and thermal conductivity of the fluid, respectively.

With the help of Eqns. (6), (11) and (12) Eqn. (18) becomes

$$
\begin{aligned}
& C_{f x}=f^{\prime \prime}(0), R a_{x}^{-1 / 4} N u_{x}=-\left[1+\frac{4}{3 N_{R}}\left\{1+\left(\theta_{r}-1\right) \theta(0)\right\}^{3}\right] \theta^{\prime}(0) \\
& R a_{x}^{-1 / 4} S h_{x}=-\phi^{\prime}(0) .
\end{aligned}
$$

Local Nusselt and Sherwood numbers could be reduced in dimensionless form and can be written as

$$
\begin{aligned}
& N u r=R a_{x}^{-1 / 4} N u_{x}=-\left[1+\frac{4}{3 N_{R}}\left\{1+\left(\theta_{r}-1\right) \theta(0)\right\}^{3}\right] \theta^{\prime}(0), ; \\
& S h r=R a_{x}^{-1 / 4} S h_{x}=-\phi^{\prime}(0) .
\end{aligned}
$$

\section{NUMERICAL METHOD AND ERROR ANALYSIS}

The highly nonlinear coupled ordinary differential Eqs. (13)-(15) subject to the boundary conditions (16) were solved numerically using the highly efficient SLLM technique (Motsa [36]). The method is based on linearizing the nonlinear system using a linear Taylor's series approximation which will essentially fetch us a linearized system of ordinary differential equations. This linearized system is then solved using Chebyshev pseudo-spectral collocation method in which computational domain is discretized using Gauss-Lobatto points and derivatives of the unknown variables are 
approximated with the help of a differentiation matrix known as Chebyshev differentiation matrix. The details of the Chebyshev pseudo-spectral collocation method can be found in the text of Trefethen [37].

In order to ascertain the accuracy of the numerical results obtained through the spectral local-linearization technique, an error analysis is performed. The infinity norm of the error in function values of two consecutive iterations is examined and is set to meet the tolerance level $\varepsilon$.

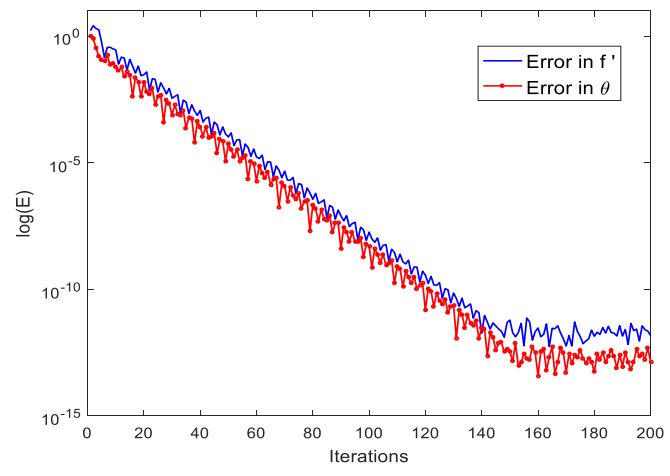

Figure 2. Maximum error $\mathrm{E}$ in (a) $f^{\prime}$ and $\theta$, and (b) $\varphi$ for different iterations

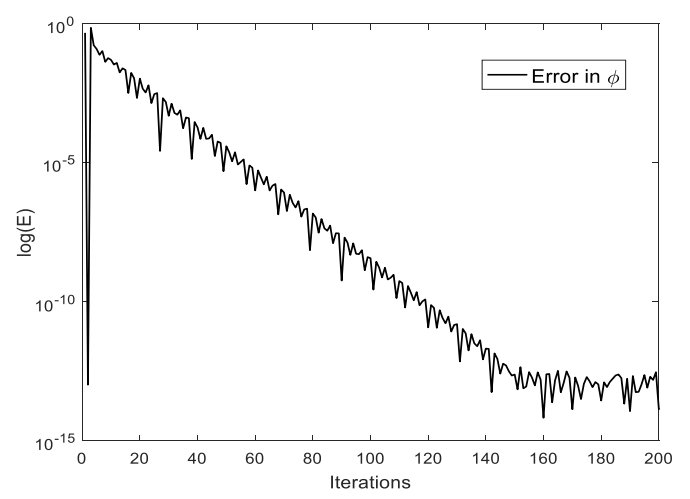

Figure 3. Maximum error $\mathrm{E}$ in $\boldsymbol{\varphi}$ for different iterations

At the $(\mathrm{r}+1)^{\text {th }}$ level of iteration, we define the maximum error $E$ as

$E=\max \left\{\left\|z_{1, r+1}-z_{1, r}\right\|_{\infty},\left\|z_{2, r+1}-z_{2, r}\right\|_{\infty}, \ldots,\left\|z_{m, r+1}-z_{m, r}\right\|_{\infty}\right\}$,

where $z_{i}, i=1,2,3, \ldots, \mathrm{m}$ are the unknown functions in the system of nonlinear equations. The values of the maximum error $E$ for different iteration levels are presented in Figures 2 and 3. It is evident from these figure that the maximum error $E$, for the present problem, becomes less than or equal to $10^{-12}$ in about 150 iterations of the spectral local linearization method which is pretty good for a physical problem of this type.

\section{RESULTS AND DISCUSSION}

In order to study the effects of non-linear thermal radiation, thermal diffusion, buoyancy force, Brownian motion, thermophoresis, temperature ratio, stretching parameter, momentum slip parameter and convective heating on fluid velocity $f^{\prime}(\eta)$ fluid temperature $\theta(\eta)$ and species concentration $\phi(\eta)$, the numerical solution for $f^{\prime}(\eta), \theta(\eta)$ and $\phi(\eta)$ are illustrated in Figs. (4) to (12) for various values of $\mathrm{N}_{\mathrm{R}}, \operatorname{Pr}, N_{b}$, $N t, \theta, \lambda, A$ and $N c$ taking $L e=5$.

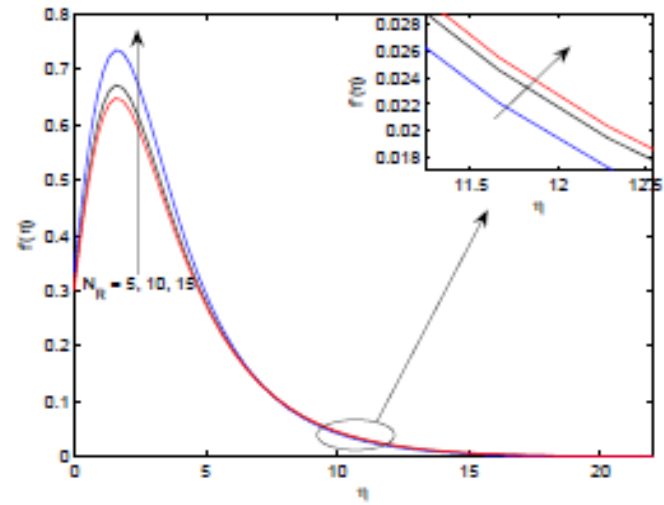

(a)

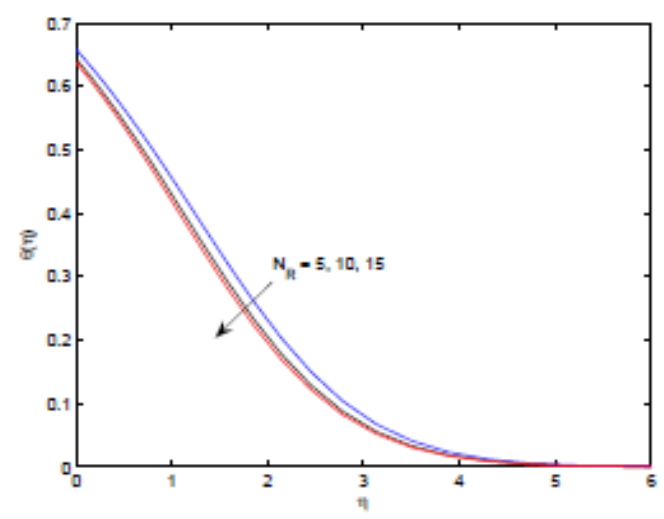

(b)

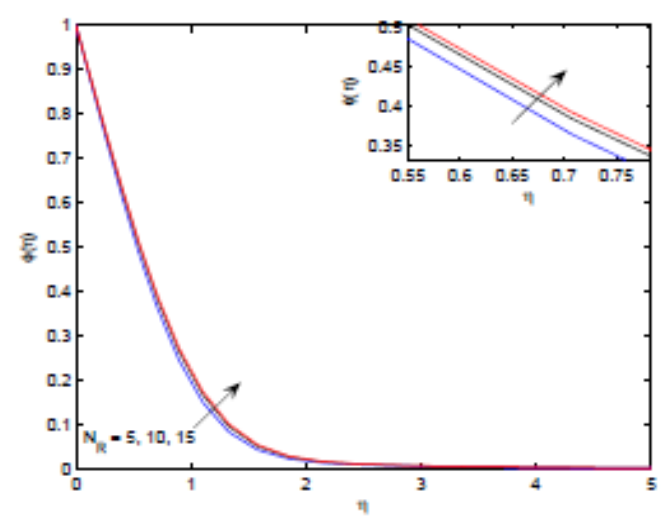

(c)

Figure 4. Velocity, Temperature and Concentration profiles when $L e=5, \operatorname{Pr}=6.785, N r=0.5, N b=0.5$, $N t=0.5, \theta_{r}=2, \lambda=0.1, A=0.5$ and $N c=0.5$

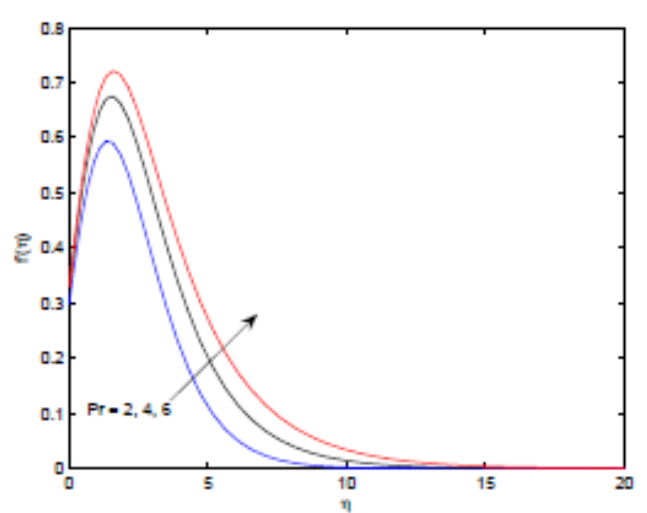

(a) 


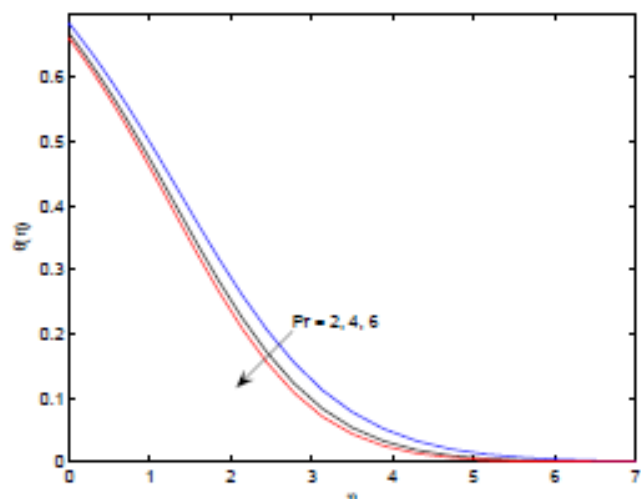

(b)

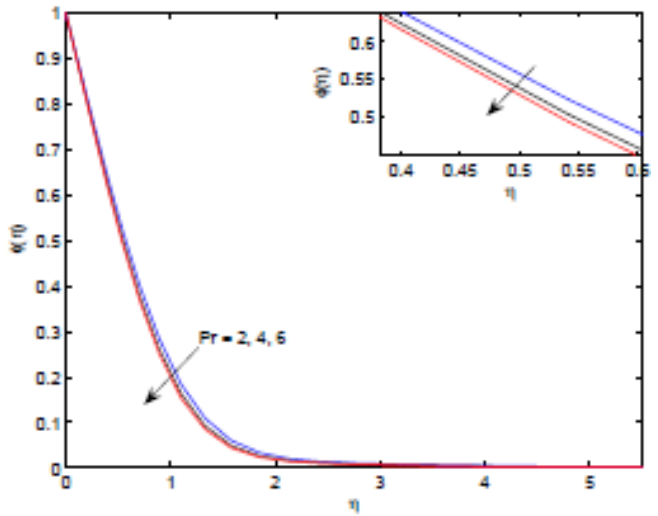

(c)

Figure 5. Velocity, Temperature and Concentration profiles when $L e=5, N_{R}=5, N r=0.5, N b=0.5, N t=0.5$,

$$
\theta_{r}=2, \lambda=0.1, A=0.5 \text { and } N c=0.5
$$

It is perceived from Figs. 4(a) to 4(c) that $f^{\prime}(\eta)$ and $\phi(\eta)$ increases as $N_{R}$ increases whereas $\theta(\eta)$ decreases as $N_{R}$ increases. Therefore, thermal radiation tends to enhance fluid velocity and nanoparticle volume concentration across the boundary layer region, whereas it has a reverse effect on fluid temperature. The reverse trend is due to the fact that the effect of radiation in equation (11) is inversely proportional to the thermal radiation parameter $N_{R}$ which signifies that for small values of $N_{R}$, there is large radiation and for large value of $N_{R}$ there is no radiation at all. It is evident from Figs. 5(a) to 5(c) that $f^{\prime}(\eta)$ increases, whereas, $\theta(\eta)$ and $\phi(\eta)$ decreases on increasing $P r$. We know, $P r$ is the ratio of viscosity to thermal diffusivity. This entails that, thermal diffusion tends to enhance fluid temperature and species concentration whereas it has a retarding effect on fluid velocity. It is noted from Figs. 6(a) to 6(c) that $\theta(\eta)$ and $\phi(\eta)$ increases on increasing $N r$. The nanofluid velocity $f^{\prime}(\eta)$ first decreases and then increases on increasing $N r$. Thus, we may conclude that, nanoparticle buoyancy force augments fluid temperature and nanoparticle volume fraction accross the boundary layer region whereas it inhibits fluid velocity near the sheet and aids in fluid velocity away from the sheet.

It is found from Figs. 7(a) to 7(c) that the increase in $\mathrm{Nb}$ causes an enhancement in $\theta(\eta)$ and $f^{\prime}(\eta)$ and a reduction in $\phi(\eta)$ accross the boundary layer region. Brownian motion generates thermal energy owing to the clash amongst tiny nanoparticles in the flow field, which enriches fluid temperature and thereby fluid velocity. Brownian diffusion urges nanoparticles to retreat from the surface of the sheet resulting in a decrease in nanoparticle volume fraction accross the boundary layer region.

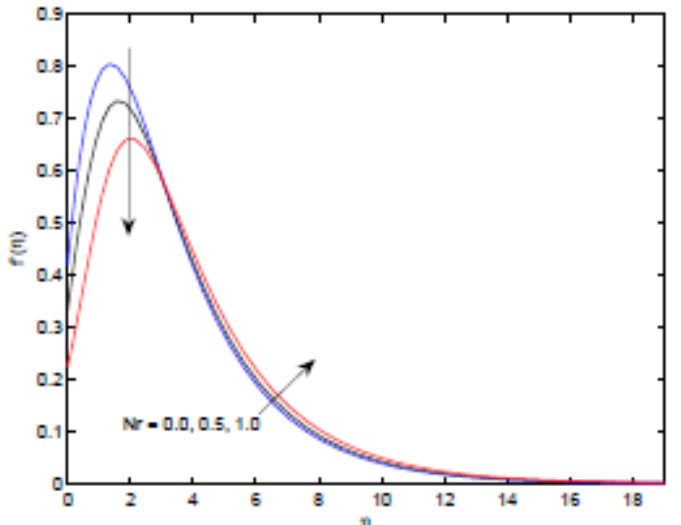

(a)

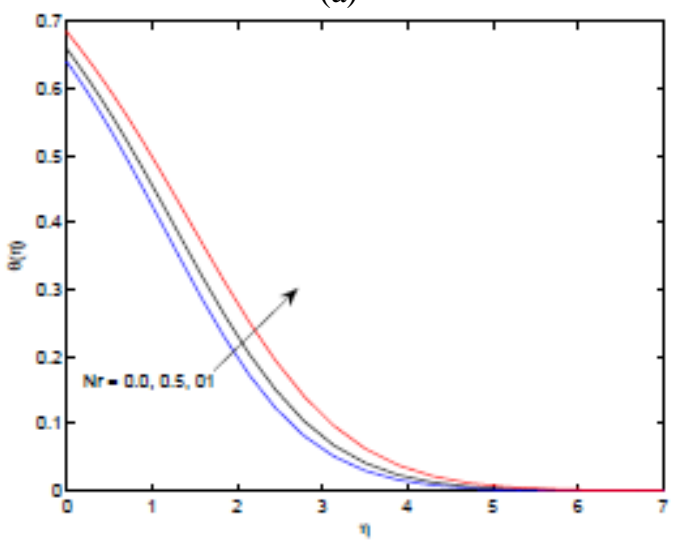

(b)

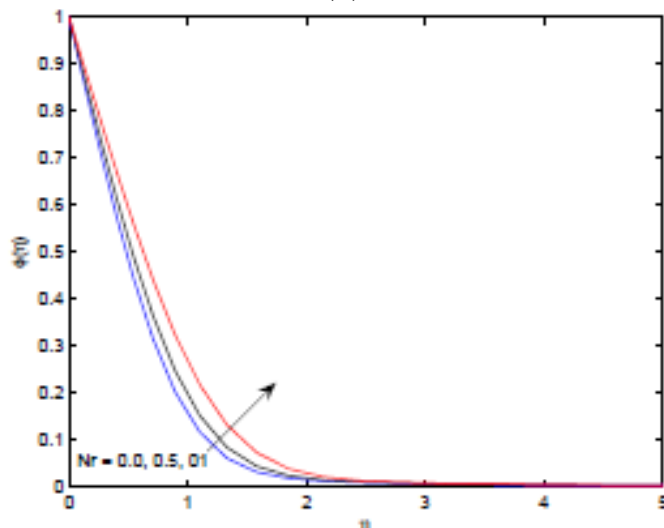

(c)

Figure 6. Velocity, Temperature and Concentration profiles when $L e=5, N_{R}=5, P r=6.785, N b=0.5, N t=0.5$,

$$
\theta_{r}=2, \lambda=0.1, A=0.5 \text { and } N c=0.5
$$

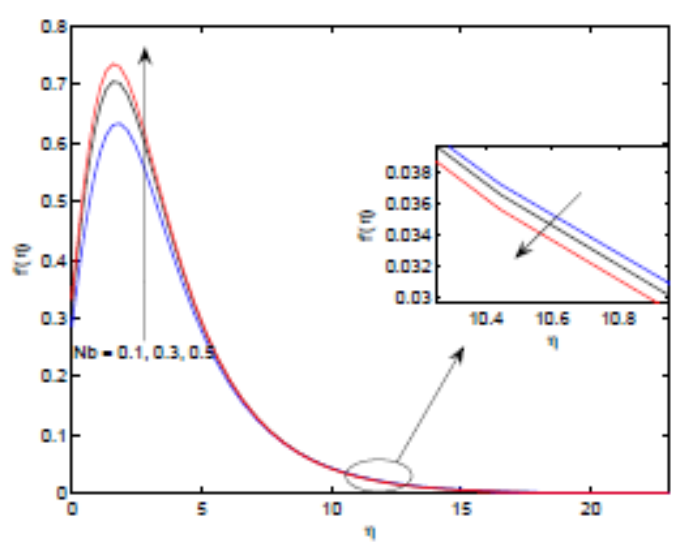

(a) 


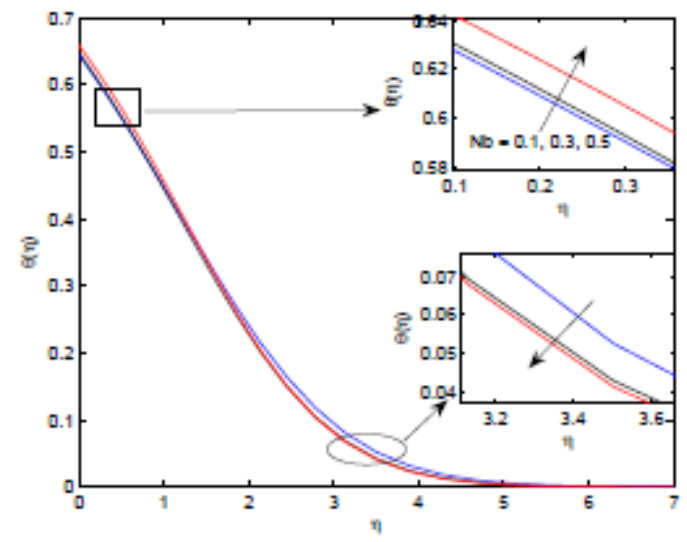

(b)

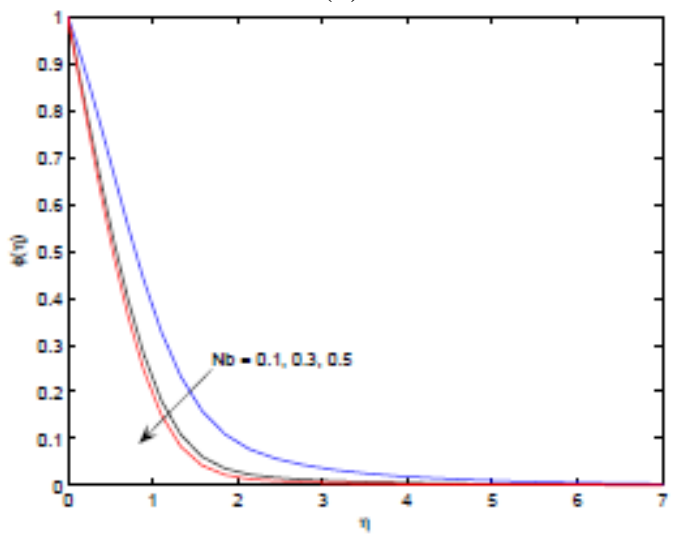

(c)

Figure 7. Velocity, Temperature and Concentration profiles when $L e=5, N_{R}=5, P r=6.785, N r=0.5, N t=0.5$,

$$
\theta_{r}=2, \lambda=0.1, A=0.5 \text { and } N c=0.5
$$

It is displayed in Figs. 8(a) to 8(c) that $f^{\prime}(\eta), \theta(\eta)$ and $\phi(\eta)$ increases as $N t$ increases. When a nanoparticle in contact with streatching sheet gets heated by the temperature of the sheet, it has a tendency to repel other nanopartcles surrounding it by the virtue of thermophoretic force. Now, an increase of $N t$ enhances the thermophoretic force which propells the nanoparticles from a region of high temperature to a region of low temperature within the boundary layer which leads to the increase of nanofluid temperature and nanoparticle volume fraction. This in turn, results in the enhancement of fluid velocity in most of the boundary layer region. Figs. 9(a) to 9(c) presents the effect of temperature ratio parameter $\theta_{r}\left(=\frac{T_{f}}{T_{\infty}}\right)$ on the fluid velocity, fluid temperature and species concentration. A value of $\theta_{r}>1$ implies a greater sheet temperature in comparison to the surrounding fluid. So, when the temperature of the sheet rises, fluid temperature increases and a convection of heat transfer towards the surrounding fluid happens which boosts the thermal buoyancy force resulting in the increase of fluid velocity. The nanoparticle volume fraction depicts an inhibiting tendency within the boundary layer region with an increase in sheet temperature.

It is noticed from Figs. 10(a) to 10(c) that an increase in the value of $\lambda$, causes a significant increase in $f^{\prime}(\eta)$ near the sheet and it becomes increasingly greater than that near the free stream, whereas, $\theta(\eta)$ and $\phi(\eta)$, decreases on increasing $\lambda$. The momentum boundary layers get wider while the thermal boundary and solutal boundary layer gets slender with an augment in the stretching parameter. It is evident in Figs. 11(a) to 11(c) that an increase in the momentum slip parameter $A$ is equivalent to a decrease in the relative velocity of the stretching sheet and the fluid. It is observed that the nanofluid velocity is an increasing function of $A$ close to sheet and it is an increasing function of $A$ in most of the boundary layer region. Species concentration and nanofluid temperature are decreasing functions of the velocity slip parameter $A$. It is depicted from the Figs. 12(a) to 12(c) that the fluid velocity, fluid temperature and species concentration increase on increasing $N c$ in the region near the sheet whereas $N c$ tends to reduce them in a region away from the sheet. This means that convective parameter helps in the development of fluid velocity, fluid temperature and species concentration near the surface of the sheet.

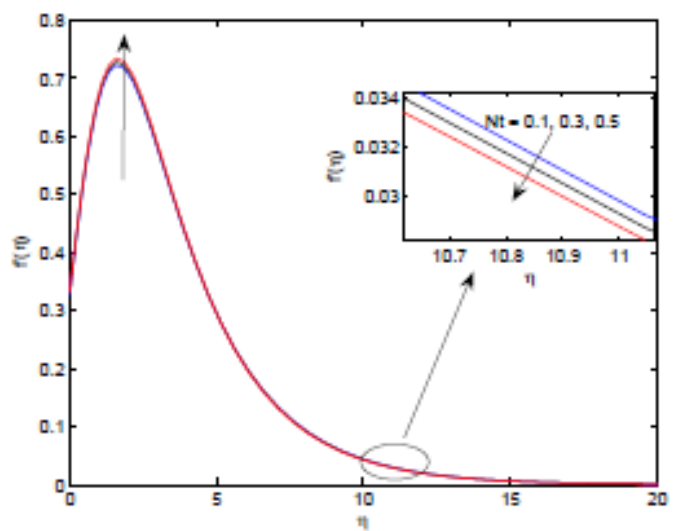

(a)

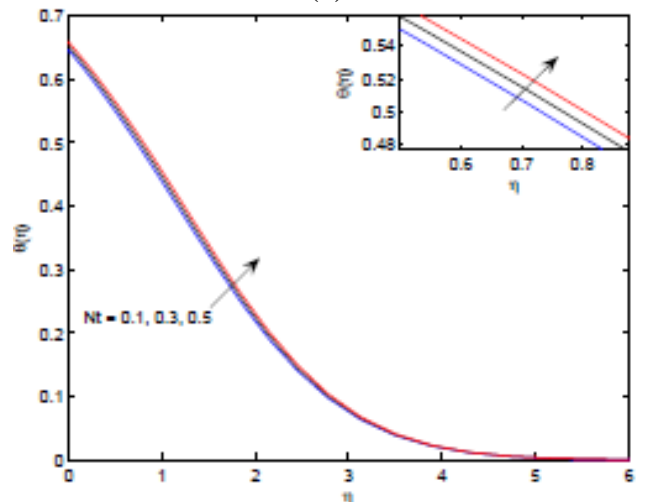

(b)

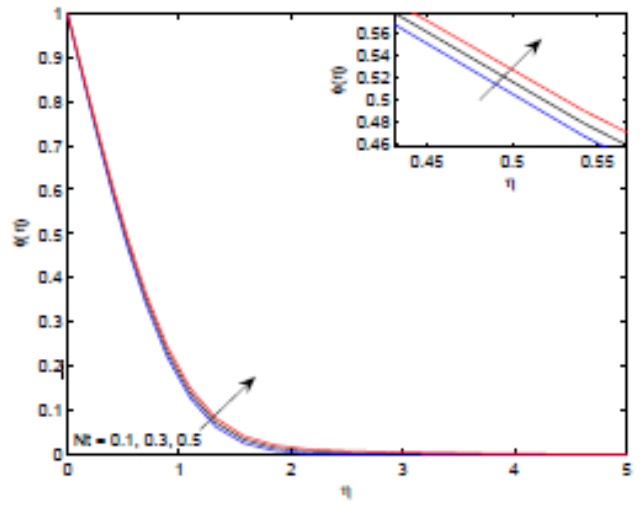

$5(\mathrm{c})$

Figure 8. Velocity, Temperature and Concentration profiles when $L e=5, N_{R}=5, P r=6.785, N r=0.5, N b=0.5$, $\theta_{r}=2, \lambda=0.1, A=0.5$ and $N c=0.5$ 


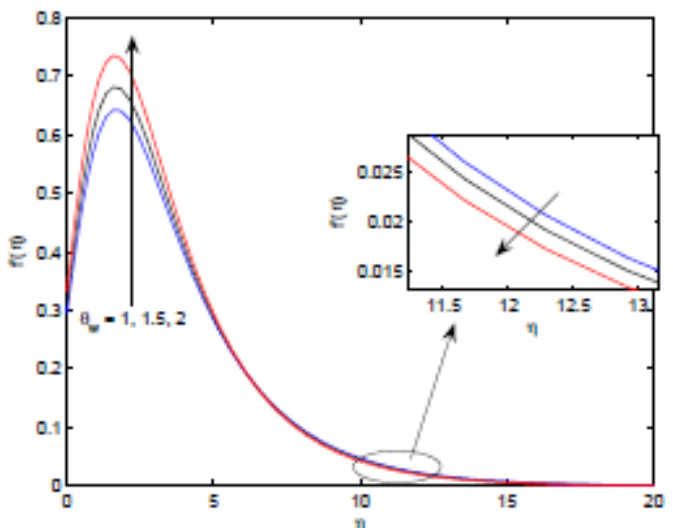

(a)

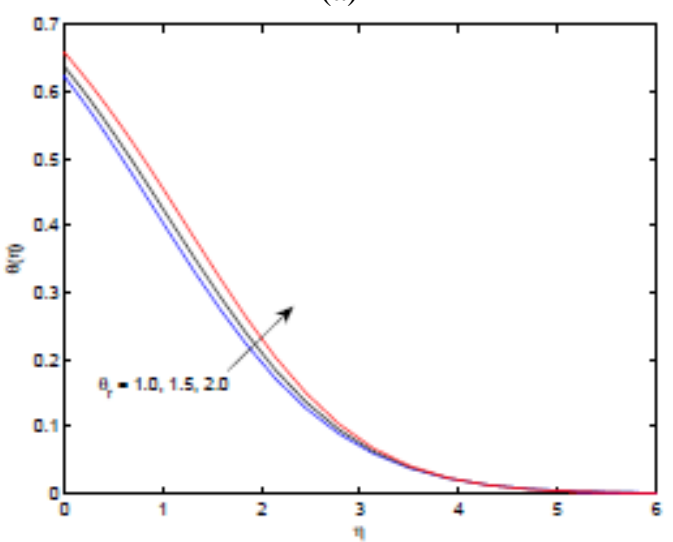

(b)

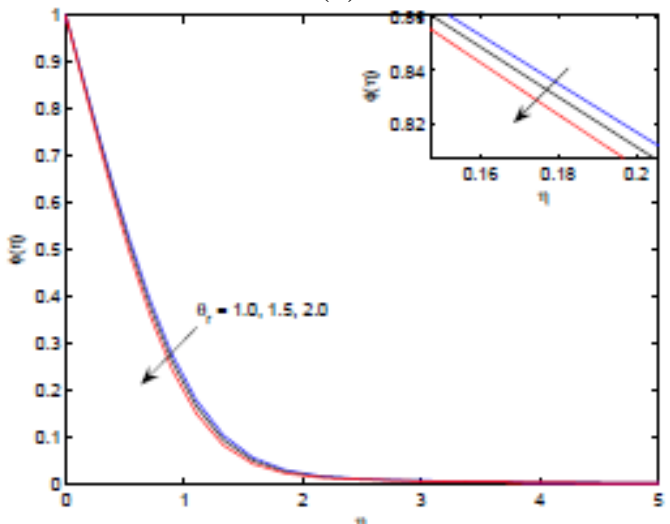

(c)

Figure 9. Velocity, Temperature and Concentration profiles when $L e=5, N_{R}=5, P r=6.785, N r=0.5, N b=0.5$, $N t=0.5, \lambda=0.1, A=0.5$ and $N c=0.5$

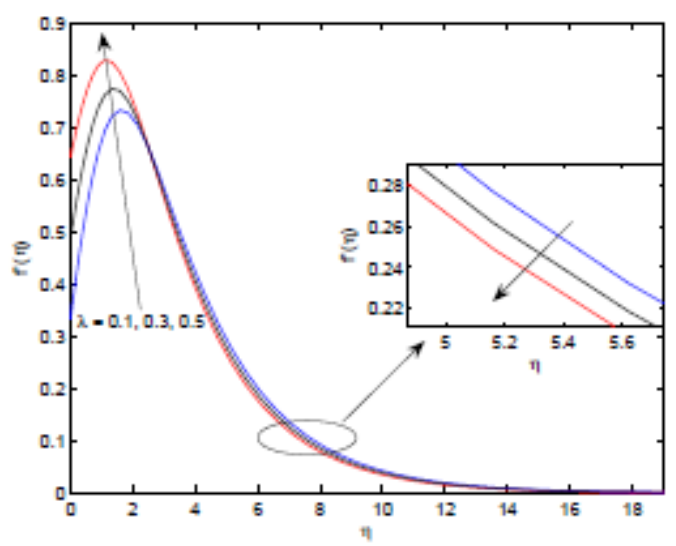

(a)

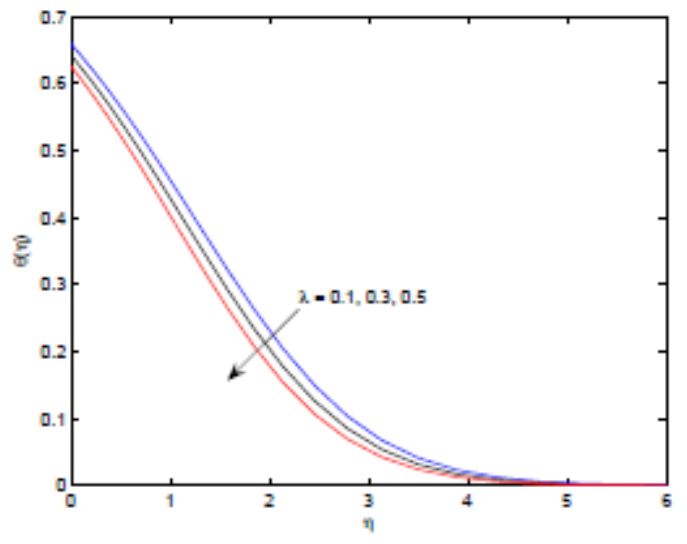

(b)

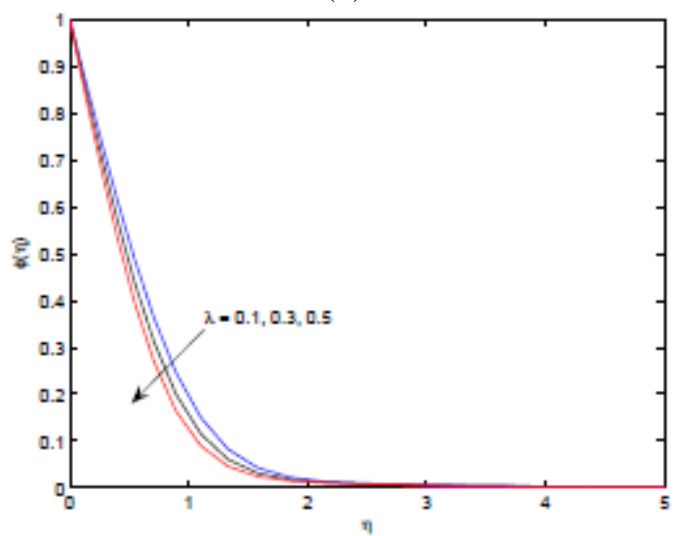

(c)

Figure 10. Velocity, Temperature and Concentration profiles when $L e=N b=0.5, N t=0.5, \theta_{r}=2, A=0.5$, $N c=0.55, N_{R}=5, P r=6.785$ and $N r=0.5$

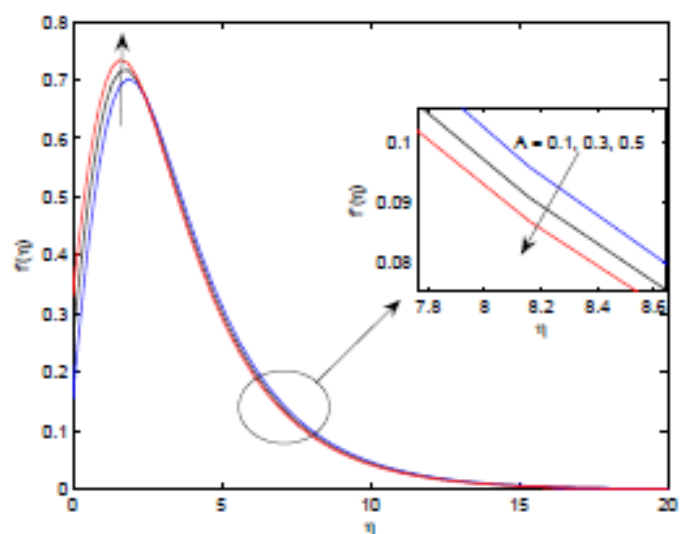

(a)

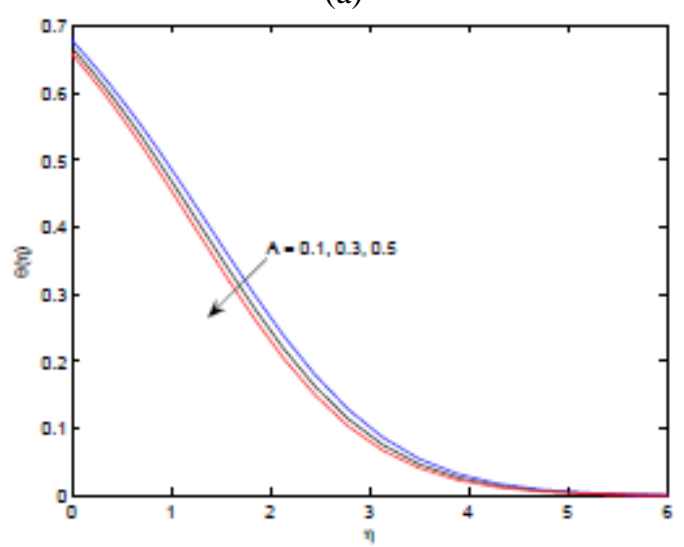

(b) 


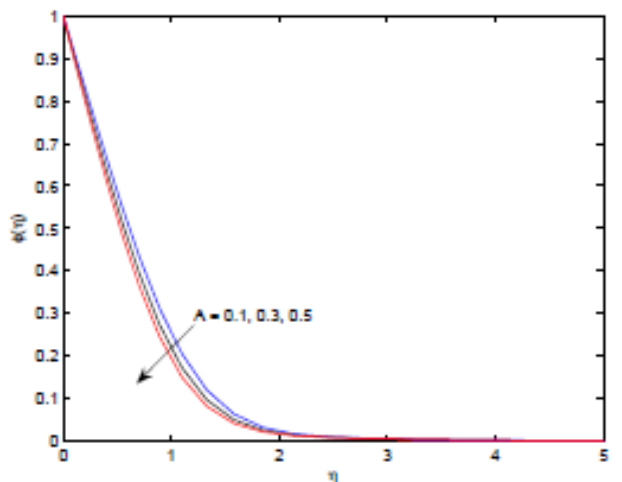

(c)

Figure 11. Velocity, Temperature and Concentration profiles when $L e=5, N_{R}=5, P r=6.785, N r=0.5, N b=0.5$,

$N t=0.5, \theta_{r}=2, \lambda=0.1$ and $N c=0.5$

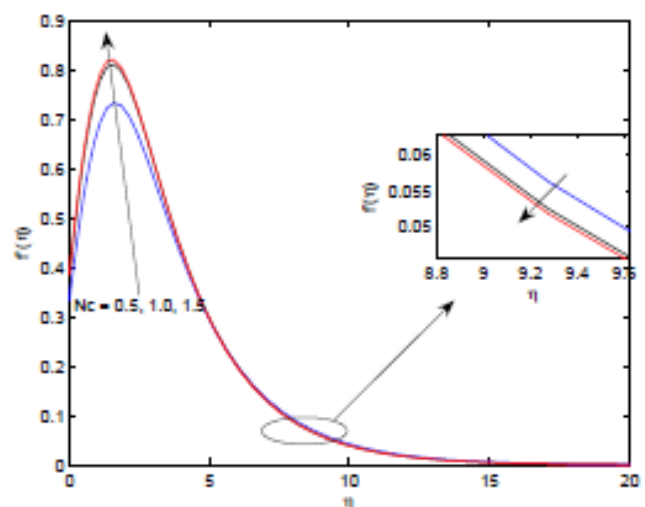

(a)

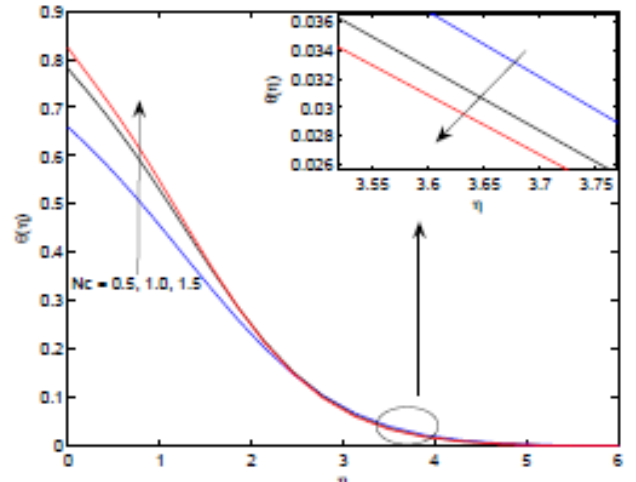

(b)

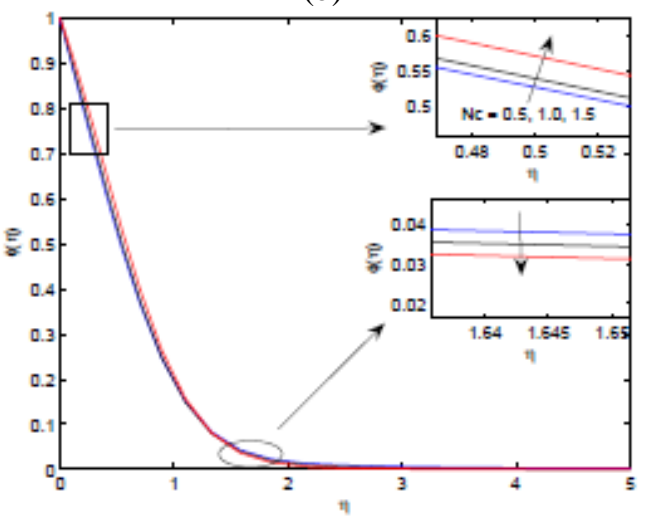

(c)

Figure 12. Velocity, Temperature and Concentration profiles when $L e=5, N_{R}=5, P r=6.785, N r=0.5, N b=0.5$,

$$
N t=0.5, \theta_{r}=2, \lambda=0.1 \text { and } A=0.5
$$

Table 1. Effects of pertinent flow parameters on $C_{f}, N u r$ and $S h r$

\begin{tabular}{|c|c|c|c|c|c|c|c|c|c|c|c|}
\hline$N_{R}$ & $P r$ & $\mathrm{Nr}$ & $\mathrm{Nb}$ & $\mathrm{Nt}$ & $\theta_{r}$ & $\lambda$ & $\mathrm{A}$ & $\mathrm{Nc}$ & $C_{f}$ & Nur & \multicolumn{1}{l}{$S h r$} \\
\hline 5 & 6.78 & 0.5 & 0.5 & 0.5 & 2 & 0.1 & 0.5 & 0.5 & 0.4651707 & 0.3780885 & 0.9766999 \\
\hline 10 & & & & & & & & & 0.4196224 & 0.2834969 & 0.9364707 \\
\hline 15 & & & & & & & & & 0.4023874 & 0.2516668 & 0.9207321 \\
\hline & 2 & & & & & & & & 0.3942130 & 0.3589477 & 0.9054326 \\
\hline & 4 & & & & & & & & 0.4367750 & 0.3709364 & 0.9490008 \\
\hline & 6 & & & & & & & & 0.4588823 & 0.3765629 & 0.9706576 \\
\hline & & 0.0 & & & & & & & 0.64053 & 0.3914825 & 1.0877007 \\
\hline & & 0.5 & & & & & & & 0.4651707 & 0.3780885 & 0.976699 \\
\hline & & 1.0 & & & & & & & 0.2501794 & 0.3585308 & 0.8198084 \\
\hline & & & 0.1 & & & & & & 0.3705462 & 0.3880395 & 0.5024957 \\
\hline & & & 0.3 & & & & & & 0.4373877 & 0.3861262 & 0.890095 \\
\hline & & & 0.5 & & & & & & 0.4651707 & 0.3780885 & 0.976699 \\
\hline & & & & 0.1 & & & & & 0.4561292 & 0.3869511 & 1.0448784 \\
\hline & & & & 0.3 & & & & & 0.4606825 & 0.3824911 & 1.0107468 \\
\hline & & & & 0.5 & & & & & 0.4651707 & 0.3780885 & 0.9766999 \\
\hline & & & & & 1.0 & & & & 0.3896824 & 0.2384759 & 0.9108293 \\
\hline & & & & & 1.5 & & & & 0.4213095 & 0.2917721 & 0.9391199 \\
\hline & & & & & 2.0 & & & & 0.4651707 & 0.3780885 & 0.9766999 \\
\hline & & & & & & 0.1 & & & 0.4651707 & 0.3780885 & 0.9766999 \\
\hline & & & & & & 0.2 & & & 0.3777369 & 0.3903687 & 1.1017037 \\
\hline & & & & & & 0.3 & & & 0.2871379 & 0.4016929 & 1.2183719 \\
\hline & & & & & & & 0.1 & & 0.5576657 & 0.3630913 & 0.8253737 \\
\hline & & & & & & & 0.2 & & 0.5080685 & 0.3714420 & 0.9094790 \\
\hline & & & & & & & 0.3 & & 0.4651707 & 0.3780885 & 0.9766999 \\
\hline & & & & & & & & 0.5 & 0.4651707 & 0.3780885 & 0.9766999 \\
\hline & & & & & & & & 1.0 & 0.5554214 & 0.5514547 & 0.8814304 \\
\hline & & & & & & & & 1.5 & 0.5709457 & 0.6947957 & 0.6994342 \\
\hline
\end{tabular}

The effects of pertinent flow parameters viz. thermal radiation parameter $N_{R}$, Prandtl number $P r$, nanoparticle buoyancy ratio $N r$, Brownian motion parameter $N b$, thermophoresis parameter $N t$, temperature ratio parameter $\theta_{r}$, 
stretching parameter $\lambda$, momentum slip parameter $A$, and convective parameter $N c$ on the flow field is tabulated in Table 1.

It is perceived from Table 1 that thermal radiation, nanoparticle buoyancy ratio, stretching of sheet and momentum slip reduces skin-friction. This can be attributed to the fact that thermal radiation, nano-particle buoyacy ratio, stretching of sheet and momentum slip has a tendency to reduce the frictional force between the surface and the fluid in contact. That is why, it is also seen that these agencies enhance fluid velocity. It is also seen that the Brownian motion, thermoporesis, convection, temperature ratio and Prandtl number enhance skin friction which is due to the fact that an increase in all these parameters increases the collision of the nanoparticles near the surface of the sheet which increases the surface drag force. Nanoparticle buoyancy ratio, temperature ratio, stretching of sheet, momentum slip and convection tend to enhance rate of heat transfer whereas Brownian motion, thermophoresis, thermal radiation and thermal diffusion has a reverse effect on it. A greater value of nanoparticle buoyancy ratio or temperature ratio enhances the rate at which the surface is cooled, thereby increasing the rate of heat transfer. Stretching of sheet increases the surface area of heat transport from the surface to ambience and hence aids in heat transfer. Momentum slip enhances heat transfer by increasing the fluid flow accross the surface while thermal convection naturally suppports heat transfer. Brownian motion and thermoporesis actually raises the ambient temperature which reduces the temperature difference between the surface and the ambience and, hence, heat transfer is reduced. Similar effect is observed with thermal radiation and thermal diffusion. Brownian motion, temperature ratio, stretching of sheet and momentum slip tend to enhance rate of mass transfer by reducing species concentration ambient to the surface of the sheet (please see the effect of these paramters on species concentration) which increases the concentration difference between the surface and ambient flow. This enhances the rate of mass transfer. Thermal radiation, thermal diffusion, nanoparticle buoyancy ratio, thermophoresis, temperature ratio and convection reduce the rate of mass transfer by increasing the solutal concentration.

\section{CONCLUSIONS}

The present paper brings out for the first time the combined effects of non-linear thermal radiation, hydrodynamic partial slip, Brownian motion and thermophoresis on two dimensional double-diffusive mixed flow of a viscous, incompressible optically thick nanofluid over a convectively heated stretching sheet. An efficient numerical scheme SLLM is applied to solve the non-linear governing equation. The numerical solution unveils many new results which are presented through graphs. Interestingly, it is found that thermal radiation reduces fluid temperature. It is due to the fact, that the effect of radiation in heat equation is inversely proportional to the thermal radiation parameter $N_{R}$. Brownian diffusion urge nanoparticles to retreat from the surface of the sheet resulting in a decrease in nanoparticle volume fraction accross the boundary layer region. Thermophoretic force enrich fluid velocity by propelling the nanoparticles from a region of high temperature to a region of low temperature. Brownian motion and thermoporesis actually raises the ambient temperature which reduces the temperature difference between the surface and the ambience and, hence, heat transfer is reduced. Stretching of the sheet causes widening of the momentum boundary layer and slandering of thermal boundary and solutal boundary layers. In addition, stretching of the sheet leads to an increase in the surface area of heat transport from the surface to ambience and, therefore, aids in heat transfer. Momentum slip enhances heat transfer by increasing the fluid flow accross the surface while thermal convection naturally supports heat transfer. Thermal radiation, nano-particle buoyacy ratio, stretching of sheet and momentum slip reduce skin-friction by decreasing the frictional force between the surface and the fluid in contact.

\section{ACKNOWLEDGMENT}

Authors are highly thankful to reviewers whose constructive suggestions helped to present the manuscript in its present form.

\section{REFERENCES}

[1] Crane LJ. (1970). Flow past a stretching plate. Z. Angrew Math Phys 21: 645-647. https://doi.org/10.1007/BF01587695

[2] Choi SUS. (1995). Enhancing thermal conductivity of fluids with nanoparticles. Proceedings of the 1995 ASME International Mechanical Engineering Congress and Exposition, San Francisco, USA ASME FED 231/MD 66, pp. 99-105.

[3] Kelson NA, Desseaux A. (2001). Effect of surface conditions on flow of a micropolar fluid driven by a porous stretching sheet. Int J Eng. Sci 39: 1881-1897. https://doi.org/10.1016/S0020-7225(01)00026-X

[4] Bhargava R, Kumar L, Takhar HS. (2003). Finite element solution of mixed convection micropolar flow driven by a porous stretching sheet. Int J Eng. Sci 41: 2161-2178. https://doi.org/10.1016/S00207225(03)00209-X

[5] Prasad KV, Vajravelu K. (2009). Heat transfer in the MHD flow of a power law fluid over a non-isothermal stretching sheet. Int J Heat Mass Transf. 52: 4956-4965. https://doi.org/10.1016/j.ijheatmasstransfer.2009.05.022

[6] Shaw S, Kameswaran PK, Sibanda P. (2013). Homogeneous-heterogeneous reactions in micropolar fluid flow from a permeable stretching or shrinking sheet in a porous medium. Boundary Value Problems 2013: 77. https://doi.org/10.1186/1687-2770-2013-77

[7] Seth GS, Sharma R, Kumbhakar B, Chamkha AJ. (2016). Hydromagnetic flow of heat absorbing and radiating fluid over exponentially stretching sheet with partial slip and viscous and Joule dissipation. Eng. Computation 33(3): 907-925. https://doi.org/10.1108/EC-05-20150122

[8] Das S, Putra N, Thiesen P, Roetzel W. (2003). Temperature dependence of thermal conductivity enhancement for nanofluids. J Heat Transfer 125: 567574. https://doi.org/10.1115/1.1571080

[9] Eastman JA, Choi SUS, Li S, Yu W, Thompson LJ. (2001). Anomalously increased effective thermal conductivity of ethylene glycol-based nanofluids containing copper nanoparticles. Appl Phys Lett 78(6): 718-720. https://doi.org/10.1063/1.1341218 
[10] Minsta HA, Roy G, Nguyen CT, Doucet D. (2009). New temperature dependent thermal conductivity data for water-based nanofluids. Int J Therm. Sci. 48: 363-371. https://doi.org/10.1016/j.ijthermalsci.2008.03.009

[11] Buongiorno J. (2006). Convective transport in nanofluids. J. Heat Transfer 128: 240-250. https://doi.org/10.1115/1.2150834

[12] Buongiorno J. (2009). A benchmark study of thermal conductivity of nanofluids. J Appl Phys 106 . https://doi.org/10.1063/1.3245330

[13] Nadeem S, Haq RU, Khan ZH. (2014). Heat transfer analysis of water-based nanofluid over an exponentially stretching sheet. Alexandria Eng. J 53: 219-224. https://doi.org/10.1016/j.aej.2013.11.003

[14] Das M, Mahatha BK, Nandkeolyar R. (2015). Mixed convection and nonlinear radiation in the stagnation point nanofluid flow towards a stretching sheet with homogenous-heterogeneous reactions effects. Procedia Engineering 127: 1018-1025. https://doi.org/10.1016/j.proeng.2015.11.451

[15] Nguyen NT, Wereley ST. (2009). Fundamentals and applications of microuidics. Artech house, London.

[16] Li D. (2008.) Encyclopedia of Microuidics and Nanofluidics. Springer USA.

[17] Ramzan M, Bilal M, Chung JD. (2017). Effects of thermal and solutal stratification on Jeffrey magnetonanofluid along an inclined stretching cylinder with thermal radiation and heat generation/absorption. International Journal of Mechanical Sciences 131: 317324. https://doi.org/10.1016/j.ijmecsci.2017.07.012

[18] Ramzan M, Yousaf F, Farooq M, Chung JD. (2016). Mixed convective viscoelastic nanofluid flow past a porous media with Soret-DuFour effects. Communications in Theoretical Physics 66(1): 133. https://doi.org/10.1088/0253-6102/66/1/133

[19] Turkyilmazoglu M. (2017). Condensation of laminar film over curved vertical walls using single and twophase nanofluid models. European Journal of Mechanics-B/Fluids 65: 184-191. https://doi.org/10.1016/j.euromechflu.2017.04.007

[20] Aziz A. (2009). A similarity solution for laminar thermal boundary over a flat plate with a convective boundary condition. Comm Nonlinear Sci and Num Simul 15: 1064-1068. https://doi.org/10.1016/j.cnsns.2008.05.003

[21] Noghrehabadi A, Pourrajab R, Ghalambaz M. (2013a). Flow and heat transfer of nanofluids over stretching sheet taking into account partial slip and thermal convective boundary conditions. Heat Mass Transf. 49: 1357-1366. https://doi.org/10.1007/s00231-013-1179-y

[22] Noghrehabadi A, Saffarian MR, Pourrajab R, Ghalambaz M. (2013b). Entropy analysis for nanofluid flow over a stretching sheet in the presence of heat generation/absorption and partial slip. J Mech Sci Tech 27: 927-937. https://doi.org/10.1007/s12206-013-0104-0

[23] Turkyilmazoglu M. (2016). Magnetic field and slip effects on the flow and heat transfer of stagnation point Jeffrey fluid over deformable surfaces. Zeitschrift für Naturforschung A 71(6): 549-556. https://doi.org/10.1515/zna-2016-0047

[24] Turkyilmazoglu M. (2017). Mixed convection flow of magnetohydrodynamic micropolar fluid due to a porous heated/cooled deformable plate: exact solutions. International Journal of Heat and Mass Transfer 106
127-134.

https://doi.org/10.1016/j.ijheatmasstransfer.2016.10.056

[25] Ramzan M, Bilal M, Farooq U, Chung JD. (2016). Mixed convective radiative flow of second grade nanofluid with convective boundary conditions: An optimal solution. Results in Physics 6: 796-804. https://doi.org/10.1016/j.rinp.2016.10.011

[26] Ramzan M, Bilal M, Chung JD, Mann AB. (2017). On MHD radiative Jeffery nanofluid flow with convective het and MSS boundary conditions. Neural Computing and Applications 1-10.

[27] Makinde OD, Aziz A. (2011). Boundary layer flow of a nanofluid past a stretching sheet with convective boundary condition. Int J of Therm. Sci 50: 1326-1332. https://doi.org/10.1016/j.ijthermalsci.2011.02.019

[28] Makinde OD, Khan WA, Khan ZH. (2013). Buoyancy effects on MHD stagnation point flow and heat transfer of a nanofluid past a convectively heated stretching/shrinking sheet. Int J Heat Mass Transf. 62: 526-533.

https://doi.org/10.1016/j.ijheatmasstransfer.2013.03.049

[29] Bhaskar Reddy N, Poornima T, Sreenivasulu P. (2014). Influence of variable thermal conductivity on MHD boundary layer slip flow of ethyleneglycol based $\mathrm{Cu}$ nanofluids over a stretching sheet with convective boundary condition. Int J Eng Math Article ID 905158. http://dx.doi.org/10.1155/2014/905158

[30] Uddin MJ, Khan WA, Ismail AIM. (2012). Scaling group transformation for MHD boundary layer slip flow of a nanofluid over a convectively heated stretching sheet with heat generation. Math Prob in Eng. 20. http://dx.doi.org/10.1155/2012/934964

[31] Mahatha BK, Nandkeolyar R, Nagaraju G, Das M. (2015). MHD stagnation point flow of a nanofluid with velocity slip, non-linear radiation and Newtonian heating. Procedia Eng. 127: 1010-1017. https://doi.org/10.1016/j.proeng.2015.11.450

[32] Ramzan M, Chung JD, Ullah N. (2017). Radiative magnetohydrodynamic nanofluid flow due to gyrotactic microorganisms with chemical reaction and non-linear thermal radiation. International Journal of Mechanical Sciences 130: 31-40. https://doi.org/10.1016/j.ijmecsci.2017.06.009

[33] Ramzan M, Bilal M, Kanwal S, Chung JD. (2017). Effects of variable thermal conductivity and non-linear thermal radiation past an Eyring Powell nanofluid flow with chemical reaction. Communications in Theoretical Physics 67(6): 723. https://doi.org/10.1088/02536102/67/6/723

[34] Uddin Md J, Hoque AKMF. (2018). Convective heat transfer flow of nanofluid in an isosceles triangular shaped enclosure with an uneven bottom wall. Chem Eng Trans 66: 403-408. https://doi.org/10.3303/CET1866068

[35] Bubbico R, Celatab GP, D’Annibaleb F, Mazzarottaa B, Menalea C (2015). Comparison of the heat transfer efficiency of nanofluids. Chem Eng Trans 43: 703-708. https://doi.org/10.3303/CET1543118

[36] Motsa SS. (2013). A new spectral local linearization method for nonlinear boundary layer flow problems. J Applied Math 1-15. http://dx.doi.org/10.1155/2013/423628

[37] Trefethen LN. (2000). Spectral Methods in Matlab, SIAM. https://doi.org/10.1137/1.9780898719598 